\title{
Frequency of Oral Sub Mucous Fibrosis and Its Correlation with the Level of Education in Patients Coming to a Tertiary Care Hospital of Karachi from January 2018 to December 2018
}

\author{
Hira Tariq ${ }^{1}$, Sanaa Ahmed ${ }^{2}$, Maria Naz ${ }^{3}$, Saad Uddin Siddiqui ${ }^{4}$, Ayesha Naureen ${ }^{3}$
}

${ }^{1}$ APPNA Institute of Public Health, Jinnah Sind Medical University, Pakistan. ${ }^{2}$ Department of Oral Medicine/Diagnosis, Karachi Medical and Dental College, Pakistan. ${ }^{3}$ Department of Oral Medicine/Diagnosis, Sindh Institute of Oral Health Sciences, Jinnah Sind Medical University, Pakistan. ${ }^{4}$ Department of Oral Medicine, Dow University of Health Sciences, Pakistan.

\begin{abstract}
Objective: To determine the frequency of oral submucous fibrosis in patients coming to dental OPD of a tertiary care hospital and to correlate the association of level of education among patients of oral submucous fibrosis. Methodology: A cross sectional study was conducted from January 2018 to December 2018 among patients coming to the dental OPD of a tertiary care hospital in Karachi. Convenience sampling was used to select patients of Oral Submucous Fibrosis and a structured questionnaire was used to collect data on level of education, age, gender and Habit. Result: A total of 4405 patients visited the OPD and 135 patients were diagnosed with OSMF based on clinical findings. Mean age of OSMF patients was 33.6 years with nearly half $47.7 \%$ having no formal education. $43.2 \%$ were skilled workers followed by $34.8 \%$ housewives and $22 \%$ were professionals. Betel nut was the most common used habit $79.5 \%$ among OSMF patients. Significant association of betelnut (p-0.001) among females $(94.5 \%)$ compared to males $(68.8 \%)$ and significant association of gutka (p-0.004) among males(24.7\%) than females (5.5\%)was observed. No significant association of level of education with substance abuse was observed. Conclusion: The finding of high frequency of betel nut usage among housewives and gutka among skilled workers is alarm some. Our literacy level despite being very low is not the sole reason of increase of substance abuse rather even the educated ones are not at par with this habit.
\end{abstract}

Keywords: OSMF- Karachi Pakistan- level of education- frequency

Asian Pac J Cancer Care, 5 (3), 157-160

\section{Introduction}

Oral submucous fibrosis is recognized by WHO as a precancerous lesion, which has a high rate of conversion into oral squamous cell carcinoma. The oral epithelium becomes atrophic and is injured easily along with fibrosis occurring in the tissue which limits the mouth opening. Problem gets much worst when the limitation increases to the level of inability of chewing and swallowing due to the fibrosis of the soft palate [1].

The disease is more prevalent in South East Asia whereas only few cases have been reported in the United States and European countries and those too are a result of the migratory Asians. Countries with the highest burden of disease are India, Taiwan, Srilanka and Pakistan. Studies done in India (Ahmadabad, Gujarat and other cities) have
Submission Date: 05/09/2020Ａcceptance Date: 07/04/2020

\footnotetext{
Corresponding Author:

Dr. Hira Tariq

APPNA Institute of Public Health, Jinnah Sind Medical University, Pakistan.

Email: hiratariq14@hotmail.com
}

clear data on the increase in the incidence of oral cancer in the past 2 decades attributed to increase in the OSF cases. Largest increase of $>30$ times in the incidence of mouth cancer has been reported from 1985 to 2010 [2].

Studies indicated that men are most commonly affected between the ages of 25-35 in both rural and urban population [2].

Studies conducted in various parts of South East Asia have established betel nut (areca nut) as the major risk factor of OSF. Betel nut (areca nut) chewing directly or in the form of pan, gutka or mawa has been reported to cause OSF. (100\% among OSF cases in Taiwan) [3]. The International Agency for Research on cancer of the 
WHO evaluated areca nut as a carcinogenic substance [4]. OSF is related to both its frequency of usage and duration that it's kept in the mouth. A survey was conducted in different socioeconomic areas to assess the knowledge of people regarding the adverse effects of betel nut which concluded that despite having knowledge about oral cancer people were reluctant to give away the habit. [5]. The billion dollar market of gutka with easy access and reduced price and the increasing incidence of OSF, constitutes a major public health risk with young being the most vulnerable [2]. However there has been no research to find out if the level of education can reduce the habit of substance abuse, resulting in reduction of Oral Submucous Fibrosis. The objective of the study is to determine the frequency of Oral Submucous Fibrosis in patients coming to dental OPD of Sindh Institute of Oral Health Sciences from January 2018 to December 2018 and to compare the level of education among patients of oral submucous Fibrosis.

\section{Materials and Methods}

A cross sectional study was conducted from January 2018 to December 2018 in patients coming to the dental OPD of Sindh Institute of Oral Health Sciences. Convenience sampling was used to select cases of oral Submucous Fibrosis. Inclusion criteria was all subjects diagnosed on basis of presence of fibrous bands causing decreased mouth opening $(<30 \mathrm{~mm})$ were included in the study. Fibrous bands were palpated through clinical examination and mouth opening measured with vernier caliper. For the collection of data, a structured questionnaire containing details of socio-demographic, habit characteristics and level of education was used.

SPSS 20 was used for data analysis. Qualitative variables were summarized as percentages and quantitative variables as mean and standard deviation. Chi- square test was used to determine the relation between independent factors (age, gender, occupation and Habit (form, frequency and duration) with dependent factor i.e. level of education among oral submucous Fibrosis patients. P-value of $<0.05$ was considered significant. Ethical approval was taken from the institutional review board and informed consent was obtained from all participants. Data was collected by trained data collectors and supervised by the principal Investigator.

\section{Results}

A total of 4405 patients visited the dental OPD from January 2018 to December 2018. Around 135 cases of oral submucous Fibrosis were identified out of 4405 based on clinical presentation of Fibrous bands and limited mouth opening. $2 \%$ of the participants did not consent to participate in the study which left the sample to be 132 cases of OSMF.

More than half of the patients with oral submucous fibrosis were males $58.3 \%$ (77) followed by $41.7 \%$ (55) females. The mean age of the patients was 33.64 (SD 12.58). Nearly half of the patients had no formal
Table 1. Sociodemographic Characteristics of Patients with OSF $(n=132)$

\begin{tabular}{lc}
\hline Variables & $\% / \mathrm{n} \&$ Mean (SD) \\
\hline Gender & \\
Males & $58.3 \%(77)$ \\
Females & $41.7 \%(55)$ \\
Age & 33.64 (SD 12.58) \\
Education & \\
No Formal Education & $47.7 \%(63)$ \\
Primary and Matric & $27.3 \%(36)$ \\
Intermediate and Above & $25 \%(33)$ \\
Occupation & \\
Housewives & $34.8 \%(46)$ \\
Skilled & $43.2 \%(57)$ \\
Professional & $22 \%(29)$ \\
\hline
\end{tabular}

education $47.7 \%$ (63) and only one third had primary and matric $27.3 \%$ (36) and intermediate and above $25 \%$ (33). Nearly half of the patients were skilled workers (laborers, carpenters, street wanders and construction workers) $43.2 \%$ (57) followed by $34.8 \%$ (46) housewives and 22\% (29) professionals (doctors, nurses, businessman, and engineers) (Table 1).

As shown in (Figure 1) more than three -forth (3/4) $79.5 \%$ of the patients ate Betel nut (betel nut), while $22 \%$ ate Pan, $16.7 \%$ Gutka and $6.8 \%$ did smoking.

The average daily consumption of Betel nut in patients of oral submucous Fibrosis was 6.10 (SD 3.9) packets and the average mean duration of use is 9.09 (SD 5.3) years. The average daily consumption of Pan is 5.5 (Standard deviation of (SD) 5.2) and average years consumed is 10.41 (SD 5.6) in patients of oral submucous fibrosis. The mean daily consumption of Gutka is 3.41 (SD 2.1) and average years consumed is 9.09 (SD 6.3). Whereas the average cigarettes smoked is 9 (SD 7.3) per day in patients of oral submucous fibrosis and the average years consumed is 11.78 (SD 3.4) (Table-2)

As shown in Table 3 When different substances were compared with independent factors we found a significant association ( $p$-value 0.001 ) of Betel nut with females showing higher frequency $(94.5 \%)$ as compared to males

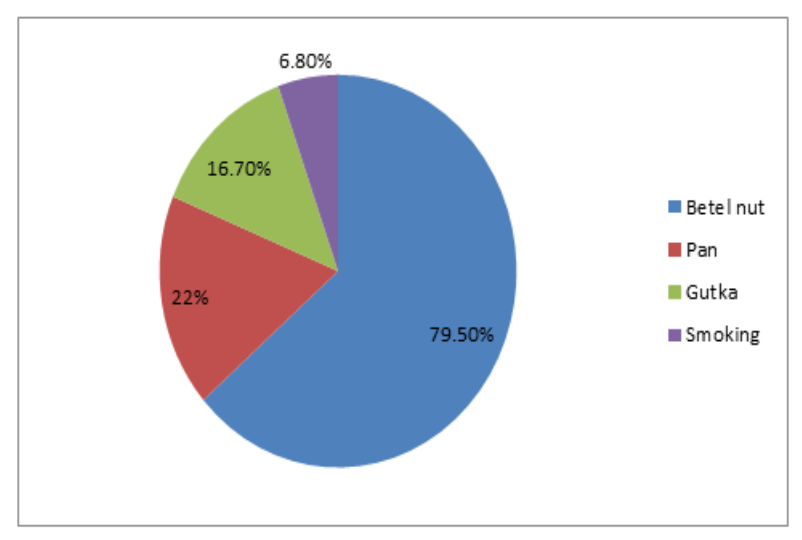

Figure 1. Frequency of Different Substance Abuse among Oral Submucous Fibrosis Patients $(n=132)$ 
Table 2. Daily Consumption and Duration of Use of Different Substance Abuse among Oral Submucous Fibrosis Patients $(\mathrm{n}=132)$

\begin{tabular}{lcc}
\hline Habits & Daily comsumption Mean (SD) & Duration (Years) of use-Mean (SD) \\
\hline Betel nut & $6.10(3.9)$ & $9.09(5.3)$ \\
Pan & $5.5(5.2)$ & $10.41(5.6)$ \\
Gutka & $3.41(2.1)$ & $9.09(6.3)$ \\
Smoking & $9(7.3)$ & $11.78(3.4)$ \\
\hline
\end{tabular}

Table 3. Comparison of Frequency of Substance Abuse with Different Factors

\begin{tabular}{|c|c|c|c|c|c|c|c|c|}
\hline Variables & $\begin{array}{c}\text { Frequency of } \\
\text { Betel nut }\end{array}$ & p-value & $\begin{array}{c}\text { Frequency of } \\
\text { Pan }\end{array}$ & p-value & $\begin{array}{c}\text { Frequency of } \\
\text { Gutka }\end{array}$ & p-value & $\begin{array}{l}\text { Frequency of } \\
\text { Smoking }\end{array}$ & p-value \\
\hline \multicolumn{9}{|l|}{ Gender } \\
\hline Male & $68.80 \%$ & 0.001 & $24.70 \%$ & 0.374 & $24.70 \%$ & 0.004 & $11.70 \%$ & 0.01 \\
\hline Female & $94.50 \%$ & & $18.20 \%$ & & $5.50 \%$ & & $1 \%$ & \\
\hline \multicolumn{9}{|l|}{ Education } \\
\hline No formal education & $79.40 \%$ & 0.598 & $19 \%$ & 0.579 & $12.70 \%$ & 0.111 & $9.50 \%$ & 0.458 \\
\hline Primary and Matric & $75 \%$ & & $27.80 \%$ & & $27.80 \%$ & & $5.60 \%$ & \\
\hline Intermediate and Above & $84.80 \%$ & & $21.20 \%$ & & $12.10 \%$ & & $3 \%$ & \\
\hline \multicolumn{9}{|l|}{ Occupation } \\
\hline Housewife & $93.50 \%$ & 0.001 & $19.60 \%$ & 0.283 & $6.50 \%$ & 0.002 & $1 \%$ & 0.014 \\
\hline Skilled & $63.20 \%$ & & $28.10 \%$ & & $29.80 \%$ & & $14 \%$ & \\
\hline Professional & $89.70 \%$ & & $13.80 \%$ & & $6.90 \%$ & & $3.40 \%$ & \\
\hline
\end{tabular}

(68.8\%). Also a significant association (p-value 0.004) was observed in the frequency of Gutka consumption with Males $(24.7 \%)$ consuming higher frequency than females $(5.5 \%)$. The association of Gender with smoking was also significant ( $p$-value 0.010 ) with males $(11.7 \%)$ as compared to females (1\%). The level of Education had no significant association with any of the substance abuse. Occupation was significantly associated ( $p$-value 0.001 ) with frequency of Betel nut in housewives $(93.5 \%)$ as compared to Skilled (63.2\%) and Professionals $(89.7 \%)$. Occupation was also significantly associated (p-value 0.002) with gutka more consumed among Skilled $(29.8 \%)$ as compared to housewives (6.5\%) and (6.9\%) in professionals. Skilled workers (14\%) also showed more frequency in smoking as compared to housewives (1\%) and professionals (3.4\%) and the association was significant (p-value 0.014 ).

\section{Discussion}

The frequency of Oral Submucous Fibrosis was found to be $3 \%$ in patients coming to dental OPD within one year. The frequency is higher than was observed in Dhanbad district of Jharkand, India which was found to be $1 \%$ in 2018 [6]. But is consistent with findings from Hunain Province, China 1\%-3\% [7]. Majority of the patients were males with an average age of 33 years, which is consistent with studies from the Asian sub-continent and also a previous study conducted in Pakistan by Sidra Mohiuddin [6-8]

We found that majority of the patients of OSMF consume betel nut $79.5 \%$ on daily basis with an average consumption of 6 packets daily for nine years. This is consistent with the study from Taiwan and India which clearly states the use of betel nut as a major etiological factor for OSMF [2-3]. However a large number of Gutka consumers $16.7 \%$ (also a product of betel quid and slime) are associated with increased of OSMF and the second major habit found in our study is the use of Gutka among OSMF patients [9]. According the Pakistan Medical association's statistics 1.5 million oral cancers occur due to the use of betel quid and gutka [13].

The use of betel nut was significantly higher in females as compared to males in our study and this finding is in contrast to previous studies conducted in Pakistan and India [1-10] which shows a high frequency among men, however our results are in line with study in Cambodia and Pacific island of Palau where women are predominant users of Betel nut [11-12]. Also the rare use of female smoking observed in our study is consistent with Cambodia [14], where a significantly low usage is observed among females than males. However the use of gutka is more among males which is also in line with previous studies [9-13].

We found that the Habits of betel nut, gutka, pan and smoking were more among those who had no formal education which is in contrast to study in India where high frequency was observed among Secondary and college students followed by illiterate [14]. However the use of gutka among skilled workers is in line with studies from India which also highlights the use of gutka and betel nut among laborers, tea sellers, wage earners and other skilled workers as compared to professionals like engineers, managers and other formally employed workers [14]. A major reason is the need of alertness and reduced hunger which these products are known to provide along 
with their soothing effects, which is a major compromise in low-income countries substituting low cost substance abuse with healthy diet [14]. However the high usage of betel nut among housewives is very much related to the familial background of consumption as highlighted in previous literature [9-14].

No association of habit with education clearly states that there is a need of awareness campaigns at school and college levels which would reduce the menace among the educated class. Also we recommend provision of low cost healthy food to the skilled and daily earners, so they won't have to kill their hunger in order to survive and rely on such substances of abuse. Moreover strict action of government is required in the commercial ban of the product with regular monitoring and follow-up.

We had limitations and the study was only a single government hospital, therefore the results cannot be generalized on the entire population of Karachi.

In conclusion, the study is only a snap shot of the current patients of OSMF coming to dental OPD of a tertiary care hospital. The finding of high frequency of betel nut usage among housewives and gutka among skilled workers is alarm some. Our literacy level despite being very low is not the sole reason of increase of substance abuse rather even the educated ones are not at par with this habit.

\section{References}

1. Mohiuddin S, Fatima N, Hosein S, Hosein M. High risk of malignant transformation of oral submucous fibrosis in Pakistani females: A potential national disaster. JPMA The Journal of the Pakistan Medical Association. 2016;66(11):1362.

2. Gupta P, Ray C, Murti P, Sinha D. Rising incidence of oral cancer in Ahmedabad city. Indian journal of cancer. 2014;51(5):67.

3. Tilakaratne WM, Ekanayaka RP, Warnakulasuriya S. Oral submucous fibrosis: a historical perspective and a review on etiology and pathogenesis. Oral Surgery, Oral Medicine, Oral Pathology and Oral Radiology. 2016 08;122(2):178191. https://doi.org/10.1016/j.oooo.2016.04.003

4. Naveed S, Syed R, Zafar A, Tariq T, Wasif N, Ibrahim S. Prevalence of (OSF) Oral Submucous Fibrosis and Risk Factors in Karachi. practice.:15-8.

5. Khan M, Bawany F, Shah S, Hussain M, Arshad M, Nisar N. Comparison of knowledge, attitude and practices of betelnut users in two socio-economic areas of Karachi. JPMA The Journal of the Pakistan Medical Association. 2013;63(10):1319-25.

6. Shivam A, Azam F, Sadiq H. Prevalence of oral submucous fibrosis among habitual gutkha and areca nut chewers in Dhanbad district. Int J Prev Clin Dent Res . 2018;5:60-2.

7. Zhang S, Li W, Gao Y, Liu Z, Liu L, Tang J, Ling T. Betelquid and oral submucous fibrosis: a cross-sectional study in Hunan province, China. Journal of Oral Pathology \& Medicine. 201205 19;41(10):748-754. https://doi. org/10.1111/j.1600-0714.2012.01166.x

8. Peng Q, Li H, Chen J, Wang Y, Tang Z. Oral submucous fibrosis in Asian countries. Journal of Oral Pathology \& Medicine. 201908 03;49(4):294-304. https://doi. org/10.1111/jop.12924

9. Niaz K, Maqbool F, Khan F, Bahadar H, Hassan F, Abdollahi
M. Smokeless tobacco (paan and gutkha) consumption, prevalence, and contribution to oral cancer. Epidemiology and health. 2017;:39.

10. Deshmukh P, Murali N, Garg B, Dongre A. Tobacco consumption among adolescents in rural Wardha: Where and how tobacco control should focus its attention? Indian Journal of Cancer. 2008;45(3):100. https://doi. org/10.4103/0019-509x.44065

11. Ikeda N, Handa Y, Khim SP, Durward C, Axell T, Mizuno T, Fukano H, Kawai T. Prevalence study of oral mucosal lesions in a selected Cambodian population. Community Dentistry and Oral Epidemiology. 1995 02;23(1):49-54. https://doi.org/10.1111/j.1600-0528.1995.tb00197.x

12. Ysaol J, Chilton J, Callaghan P. A survey of betel nut chewing in Palau. . ISLA: A Journal of Micronesian Studies. 1996 Jan;4(1):244-55.

13. Afridi S, Afzal M, Naqvi S, Rehan F, Wali A. Prevalence of Gutka; A Form of Smokeless Tobacco's Consumption Amongst Patients Seen at Baqai Dental College Hospital, Karachi. Pakistan Oral \& Dental Journal. 2018 Sep 1;38(3).

14. Hallikeri K, Naikmasur V, Guttal K, Shodan M, Chennappa $\mathrm{N}$. Prevalence of oral mucosal lesions among smokeless tobacco usage: A cross-sectional study. Indian Journal of Cancer. 2018;55(4):404. https://doi.org/10.4103/ijc. ijc_178_18

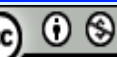

This work is licensed under a Creative Commons AttributionNon Commercial 4.0 International License. 